\title{
Synthesis, Characterization and Theoretical Study of 1,2(2,2-dihydroxy benzelidenamine) Phenyl Complexes
}

\author{
Dina A. Najeeb ${ }^{1}$, Ahmed Ahmed ${ }^{1}$ and Muhammad Rahimi Yusop ${ }^{2}$ \\ ${ }^{1}$ Department of Chemistry, College of Science, Al-Nahrain University, Baghdad-Iraq. \\ ${ }^{2}$ School of Chemical Sciences and Food Technology, Faculty of Science and Technology, \\ University Kebangsaan Malaysia, 43600 UKM Bangi, Selangor, Malaysia.
}

\begin{abstract}
New schiff base and its metal complexes of $\mathrm{Co}(\mathrm{II}), \mathrm{Ni}(\mathrm{II}), \mathrm{Fe}(\mathrm{II})$ and $\mathrm{Cu}(\mathrm{II})$ has been synthesized from $O$-phenylenediamine and $O$-hydroxyl benzaldehyde. The ligand and its complexes were described the distinctive nature of element by elemental analysis (C,H,N), FTIR, UV-Vis, and magnetic susceptibility. Hyperchem-7 software was used in this project for a theoretical treatment of the synthesized complexes under gas phase condition. PM3 method was used to calculate: heat of formation $(\Delta \mathrm{Hf})$, binding energy $\left(\Delta \mathrm{E}_{\mathrm{b}}\right)$ and total energy $(\Delta \mathrm{ET})$ for both ligand and its complexes at $298 \mathrm{~K}$. Additionally, the electrostatic potential of the free ligand (L) was calculated to see the active sites of the product complexes. According to the results of this research, the produced complexes form [ML] type composition where L ligand=1,2(2,2-dihydroxy benzeliden amine). Phenyl and $\mathrm{M}=\mathrm{Co}, \mathrm{Ni}, \mathrm{Fe}$ and $\mathrm{Cu}$. [DOI: 10.22401/JNUS.20.3.03]
\end{abstract}

Keywords: Metal complexes, Schiff base, Semiepirical $\mathrm{PM}_{3}$, Hyperchem.7, Theoretical Study.

\section{Introduction}

The methods of the synthesis of new transition metal complexes have been extensively studied due to their probable applications in broad ranges of science. Moreover, Schiff base and its ligands have the ability to coordinate with different metals [1-4]. The necessity of Schiff base ligands and their metal complexes are due to the range of applications such as catalysts [5,6], medicine $[7,8]$, crystal engineering [9], anti-corrosion agent [10,11]. Schiff bases are broadly explored due to the flexibility in synthesis methods, and also due to its selectivity and sensitivity for the metal ion. Furthermore, Schiff bases possesses similarities in structure with natural biological compounds in presence of azomethine group (-N=CH-) which imports in explaining the mechanism of transformation and racemization reaction in terms of biology $[12,13]$. Oxygen, nitrogen etc. are the donor's centers in Schiff bases chelation for the synthesis of their metal complexes which have potential biological activities [14].

\section{Experimental}

The chemical materials that have been used in this project were analar analytical stander and purchase from Sigma-Aldrich chemical industry. The solvents used were distilled in the purpose of high purity to be use in any test in this research under standard procedures. IR spectrometry from shimadzu (FTIR-8300) spectrophotometer were used with $\mathrm{KBr}$ medium disk. Ethanol was used as a reference solution in all the UV-Vis spectrometric measurements of all the complexes using Shimadzu UV-1650PC spectrophotometer with (200-1000) $\mathrm{nm}$ range. The magnetic susceptibility was measured for the newly prepared complexes at $25 \mathrm{C}^{\circ}$ using (Magnetic susceptibility Balance) from Johnson Maltery.

\section{Preparation of ligand $(\mathrm{L})$}

A mixture of $o$-aminopyramidine $(0.021 \mathrm{~mol}$, $2 \mathrm{~g})$ and $o$-hydroxyaldehyde $(0.021 \mathrm{~mol}, 4.58 \mathrm{~g})$ dissolved in ethanol and acidified with several drops of glacial acetic acid, after that the reaction mixture was refluxed for 6-hrs by air condenser. Then the precipitated be washed, filtered and re-crystallized by ethanol, and become dry in desiccator over anhydrous (calcium chloride) vacuum. The general arrangement of ligand obtained from chemical analysis and spectral methods were shown in Scheme (1). 


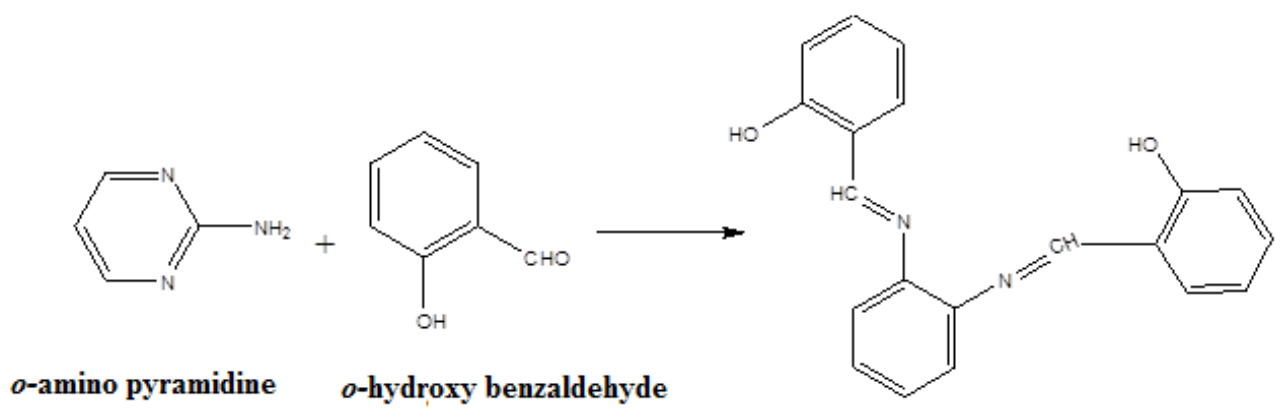

Scheme (1) Reaction scheme of the preparation ligand.

\section{Metal complexes Preparation procedure}

New complexes of the cationic ions of $\mathrm{Fe}(\mathrm{II}), \mathrm{Co}$ (II), Ni (II) and $\mathrm{Cu}(\mathrm{II})$ have been prepared by reacting solution of metal halides with solutions of ligands in molar ratio $1: 1$. The colored complexes which were separated under relatively low temperature, then the product complexes were filtered and washed with ethanol to remove unreacted chemicals, finally the precipitate were allowed to dried in oven.

\section{Result and Discussion}

Table (1) illustrates all the ligand and their complexes physical properties tested in this project. All metal complexes are colored, stable in air at room temperature. These are incapable of being dissolved in polar solvent and soluble in organic solvents and all of them are non-electrolytes in DMF [15].

Table (1)

Physical and Analytical Data measurements of the newly prepared Schiff Base and their metal Complexes.

\begin{tabular}{|c|c|c|c|c|c|c|c|c|c|c|}
\hline \multirow{2}{*}{ Compound } & \multirow{2}{*}{$\begin{array}{l}\text { Molecular } \\
\text { Weight }\end{array}$} & \multirow{2}{*}{$\begin{array}{l}\text { Product } \\
\text { color }\end{array}$} & \multirow{2}{*}{$\begin{array}{c}\% \\
\text { products }\end{array}$} & \multirow{2}{*}{$\begin{array}{l}\text { M.Pt } \\
\left(\mathbf{C}^{\circ}\right)\end{array}$} & & & $\begin{array}{c}\text { Found } \\
\text { (Calc) \% } \\
\end{array}$ & & & \multirow{2}{*}{$\begin{array}{c}\text { (Molar) } \\
\text { (conductance) } \\
\text { Ohm }^{-1} \mathrm{~cm}^{2} \\
\text { mol }^{-1} \times \mathbf{1 0}^{-3}\end{array}$} \\
\hline & & & & & $\mathrm{C}$ & $\mathrm{H}$ & $\mathrm{N}$ & $\mathrm{O}$ & $\mathrm{M}$ & \\
\hline Ligand(L) & 316 & Brown & 77 & 235 & $\begin{array}{c}75.00 \\
(75.94)\end{array}$ & $\begin{array}{c}5.04 \\
(5.06) \\
\end{array}$ & $\begin{array}{c}8.83 \\
(8.86) \\
\end{array}$ & $\begin{array}{c}10.10 \\
(10.12)\end{array}$ & ------ & \\
\hline$\left[\mathrm{FeLCl}_{2}\right]$ & 442.54 & Brown & 62 & 265 & $\begin{array}{c}54.20 \\
(54.23) \\
\end{array}$ & $\begin{array}{c}3.13 \\
(3.16) \\
\end{array}$ & $\begin{array}{c}6.31 \\
(6.32) \\
\end{array}$ & $\begin{array}{c}7.22 \\
(7.23) \\
\end{array}$ & $\begin{array}{c}12.55 \\
(12.57) \\
\end{array}$ & 1.34 \\
\hline$\left[\mathrm{CoLCl}_{2}\right]$ & 445.83 & Green & 63 & 258 & $\begin{array}{c}53.71 \\
(53.83) \\
\end{array}$ & $\begin{array}{c}3.12 \\
(3.14) \\
\end{array}$ & $\begin{array}{c}6.24 \\
(6.28) \\
\end{array}$ & $\begin{array}{c}7.10 \\
(7.17) \\
\end{array}$ & $\begin{array}{c}13.19 \\
(13.21) \\
\end{array}$ & 4.95 \\
\hline$\left[\mathrm{NiLCl}_{2}\right]$ & 445.59 & Red & 69 & 267 & $\begin{array}{c}53.85 \\
(53.86)\end{array}$ & $\begin{array}{c}3.12 \\
(3.14)\end{array}$ & $\begin{array}{c}6.25 \\
(6.28)\end{array}$ & $\begin{array}{c}7.16 \\
(7.18) \\
\end{array}$ & $\begin{array}{c}13.13 \\
(13.17) \\
\end{array}$ & 3.14 \\
\hline$\left[\mathrm{CuLCl}_{2}\right]$ & 450.45 & Green & 69 & 278 & $\begin{array}{c}53.25 \\
(53.28) \\
\end{array}$ & $\begin{array}{c}3.10 \\
(3.10)\end{array}$ & $\begin{array}{c}6.20 \\
(6.21)\end{array}$ & $\begin{array}{c}7.10 \\
(7.10)\end{array}$ & $\begin{array}{c}14.10 \\
(14.10)\end{array}$ & 4.03 \\
\hline
\end{tabular}

\section{[IR spectra]}

The main character of the coordination ligand and their metal ions has been determined by IR spectra as shown in Table (2). Two strong absorption bands at $1656 \mathrm{~cm}^{-1}$ and $3417 \mathrm{~cm}^{-1}$ is an indication of the azomethine $(-\mathrm{HC}=\mathrm{N}-)$ and phenolic $(-\mathrm{OH})$ group respectively as in Schiff base ligand. Furthermore, the hydroxyl group in ligand (I) was absorbed at $\left(3417 \mathrm{~cm}^{-1}\right)$, whereas disappeared in the IR-spectrum of the Schiffbase complexes which might be due to the deprotonating and coordination of the main matrix to the metal ion to form (M-O).

In addition, the spectra of the prepared complexes show some new bands in between $\left(605-642 \mathrm{~cm}^{-1}\right),\left(540-585 \mathrm{~cm}^{-1}\right)$ and (388$329 \mathrm{~cm}^{-1}$ ) which might be because of the formation of (M-O), (M-N) [16] and (M-Cl) chemical bonds [17-21]. 
Table (2)

IR Spectral Measurements of ligand and their complexes.

\begin{tabular}{||c||c||c|c||c|c||}
\hline Compound & v (-OH) & vC=N & vM-O & vM-N & vM-Cl \\
\hline \hline Ligand & 3417 & 1656 & ---- & ----- & ----- \\
\hline \hline$\left[\mathrm{FeLCl}_{2}\right]$ & & 1615 & 605 & 540 & 388 \\
\hline$\left[\mathrm{CoLCl}_{2}\right]$ & & 1600 & 624 & 557 & 368 \\
\hline$\left[\mathrm{NiLCl}_{2}\right]$ & & 1598 & 637 & 573 & 346 \\
\hline \hline$\left[\mathrm{CuLCl}_{2}\right]$ & & 1590 & 642 & 585 & 329 \\
\hline
\end{tabular}

Electronic spectra and magnetic susceptibility of the complexes

The ligand (L) in ethanol was exhibited two sets of highly intense bands, the first one appeared at 36359 and $38613 \mathrm{~cm}^{-1}$, and the other bands set appeared at 32998 and $31655 \mathrm{~cm}^{-1}$ respectively. The first bands group might be attributed to $\pi \rightarrow \pi^{*}$ transitions of the carbonyl group also might be due to conjugated ring system. However, the second two bands might be related to $\mathrm{n} \rightarrow \pi^{*}$ transition which masked by the extension of the second band set [22]. The iron (II) complex electronic spectrum absorption at $11764 \mathrm{~cm}^{-1}$ band assignable to the ${ }^{5} \mathrm{~T}_{2 \mathrm{~g}} \rightarrow{ }^{5} \mathrm{E}_{\mathrm{g}}$ transition consistent with an octahedral geometry for iron (II) complex [23-25].

The room temperature magnetic moment $(5.22 \mu \mathrm{B})$ corresponds to an octahedral geometry of iron (II). Electronic spectra of Co(II) complex exhibit three absorbance peaks at $22779 \mathrm{~cm}^{-1}, 16339 \mathrm{~cm}^{-1}$ and $14925 \mathrm{~cm}^{-1}$. These absorbance maxima due to ${ }^{4} \mathrm{~T}_{1 \mathrm{~g}}(\mathrm{~F}) \rightarrow{ }^{4} \mathrm{~T}_{1 \mathrm{~g}}(\mathrm{P})$, ${ }^{4} \mathrm{~T}_{1 \mathrm{~g}}(\mathrm{~F}) \rightarrow{ }^{4} \mathrm{~A}_{2 \mathrm{~g}}(\mathrm{~F})$ and ${ }^{4} \mathrm{~T}_{1 \mathrm{~g}}(\mathrm{~F}) \rightarrow{ }^{4} \mathrm{~T}_{2 \mathrm{~g}}$, transitions correspondingly, because of the characteristics of the $\mathrm{Co}$ (II) metal ion octahedral geometry [26,27]. Magnetic moment is found to be $3.85 \mu \mathrm{B}$. A broad low intensity band noticeable at $14798 \mathrm{~cm}^{-1}$ which is caused by the d-d transition of the $\mathrm{Cu}$ (II) ion, this band is of low molar absorptivity being Laporte forbidden and could be assigned to $\mathrm{Eg} \rightarrow{ }^{2} \mathrm{~T}_{2 \mathrm{~g}}$ transition. The band electronic absorption at $32268 \mathrm{~cm}^{-1}$ might be due to (LMCT) ligand - metal charge transfer which is belonging typically for copper (II) complexes with nitrogen donors.

The magnetic moment value at $1.58 \mu \mathrm{B}$ of the complex at $25 \mathrm{C}^{\circ}$ shows similar value to the octahedral structure for the $\mathrm{Cu}$ (II) ion [28]. Additionally, the electronic spectrum measurement of the $\mathrm{Ni}$ (II) complex might be assigned to the structure of the octahedral geometry. However, the spectrum measurements of $\mathrm{Ni}(\mathrm{II})$ complex identified two bands at 16722 and $22727 \mathrm{~cm}^{-1}$, refer to the transitions ${ }^{3} \mathrm{~A}_{2 \mathrm{~g}}(\mathrm{~F}) \rightarrow{ }^{3} \mathrm{~T}_{1 \mathrm{~g}}(\mathrm{~F})$ and, ${ }^{3} \mathrm{~A}_{2 \mathrm{~g}}(\mathrm{~F}) \rightarrow{ }^{3} \mathrm{~T}_{1 \mathrm{~g}}(\mathrm{P})$ respectively [29] provided further support by The magnetic susceptibility value in the range of $3.10 \mu \mathrm{B}$ of the complexes. The proposed structures for the complexes that have been prepared are shown in Fig. (2).

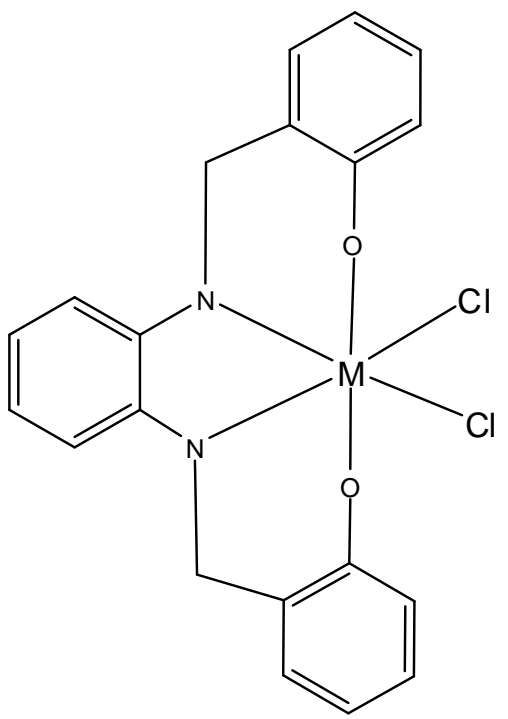

Scheme (2): The suggest structure of the complexes where $\mathrm{M}=\mathrm{Fe}, \mathrm{Co}, \mathrm{Ni}$, and $\mathrm{Cu}$ ligand=1,2(2,2-dihydroxy benzeliden amine). Phenyl.

\section{Theoretical studies of (L) ligand and their metal complexes}

Hyperchem-7 software was used for semiempirical calculation for the purpose of measuring: heat of formation $\left(\Delta \mathrm{H}^{\circ} f\right)$, binding energy $(\Delta \mathrm{E} b)$ and total energy for ligand and its synthesized complexes, in addition to calculate the molecular orbita HOMO and LUMO for ligand and their complexes as in Table (3) [30]. The electrostatic potential (E.P) with the energy interaction of the molecular 
system with a positive charged center. (E.P) can be used to find reaction sites in a molecule; the positively charged molecules have a tendency to attack a molecule when its electro static potential site is powerfully negative i.e. electrophonic interaction [31]. E.P of ligand (L) and their complexes could be calculated and plotted as 2D contour to study the reactive sites of the molecules as in Fig.(4). The results of calculations show that the LUMO of transition metal ions prefer to react with the $\mathrm{HOMO}$ of $\mathrm{O}$ and $\mathrm{N}$ atoms of free ligands (L).

Table (3)

Total energy, Binding, Heat of formation calculations in $\mathrm{kcal} / \mathrm{mol}$ and the Energy of HOMO, LUMO levels.

\begin{tabular}{|c||c|c|c||c|c|}
\hline Compound & Total energy & $\begin{array}{c}\text { Binding } \\
\text { energy }\end{array}$ & $\begin{array}{c}\text { Heat of } \\
\text { formation }\end{array}$ & HOMO & LUMO \\
\hline \hline Ligand & -88362.234658 & 4854.897625 & 9968.8796934 & -5.478122 & -1.121363 \\
\hline $\mathrm{Fe} \mathrm{com}$. & -10032.733743 & 6123.552910 & 11152.476910 & -7.85801 & -1.334127 \\
\hline $\mathrm{Co} \mathrm{com}$. & -93808.158326 & 5674.285088 & 21160.821088 & -8.406527 & 4.21399 \\
\hline $\mathrm{Ni} \mathrm{com}$. & -111989.7009 & 6252.970674 & 11285.394674 & -7.594781 & 2.558232 \\
\hline $\mathrm{Cu}$ com. & -11383.5995524 & 8150.9244926 & 13213.350492 & -7.503585 & -4.425163 \\
\hline
\end{tabular}

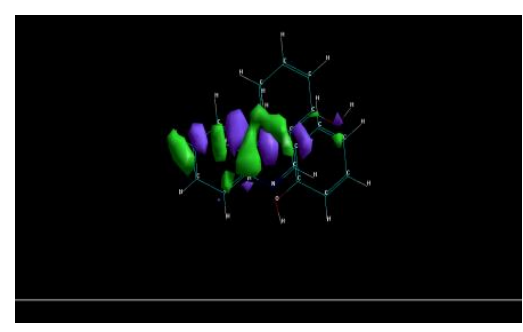

Homo of ligand

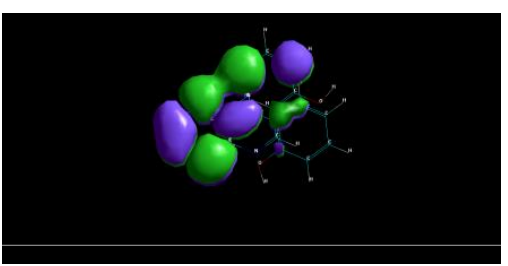

Lumo of ligand

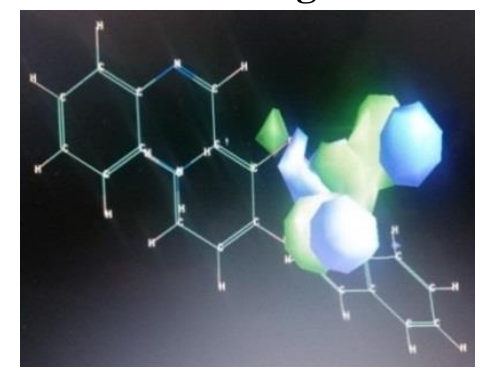

Homo of iron complex

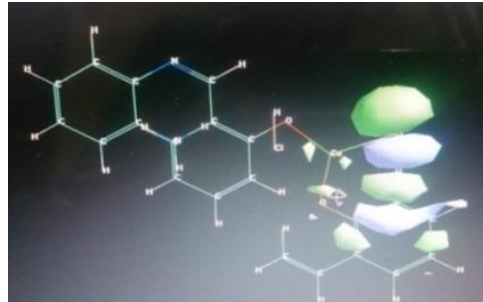

Homo of cu complex

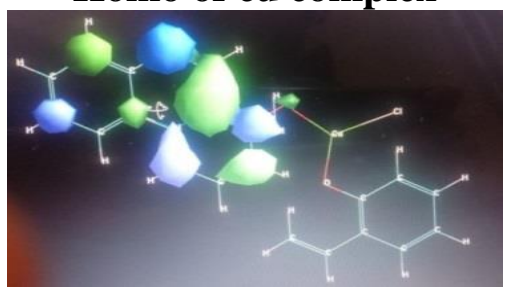

Lumo of $\mathrm{Cu}$ Complex

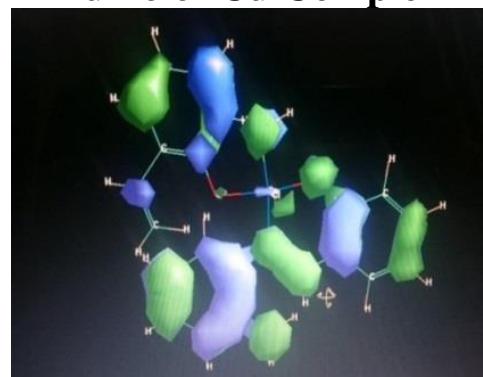

Lumo of iron complex

Scheme (3): HOMO and LUMO for ligand and its complexes. 


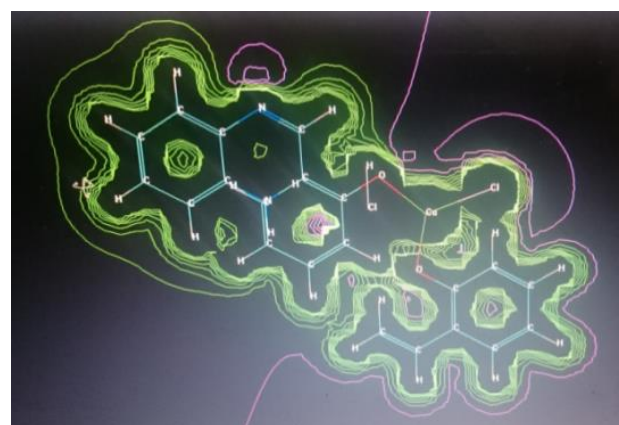

Electrostatic potential of $\mathrm{Cu}$

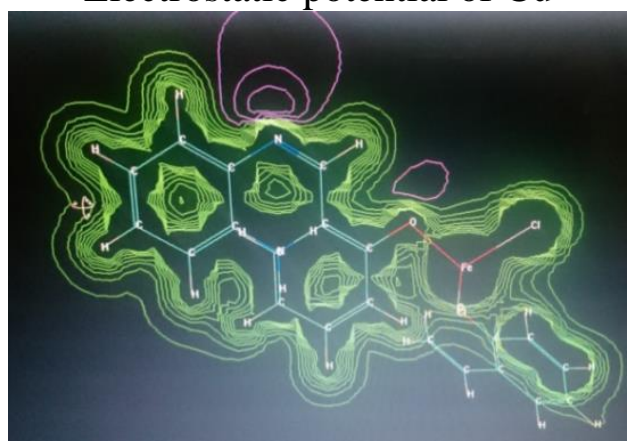

Electrostatic potential of $\mathrm{Fe}$

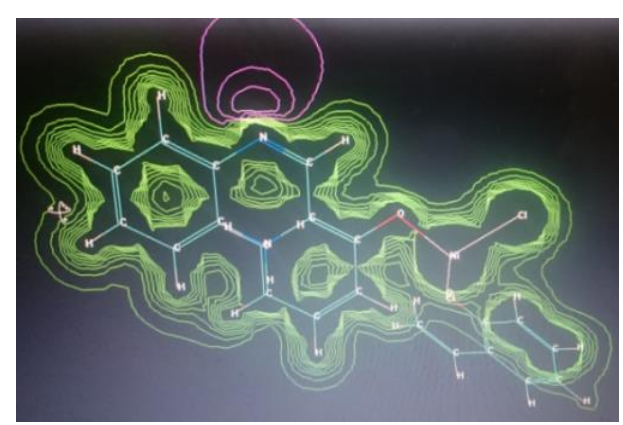

Electrostatic potential of $\mathrm{Ni}$

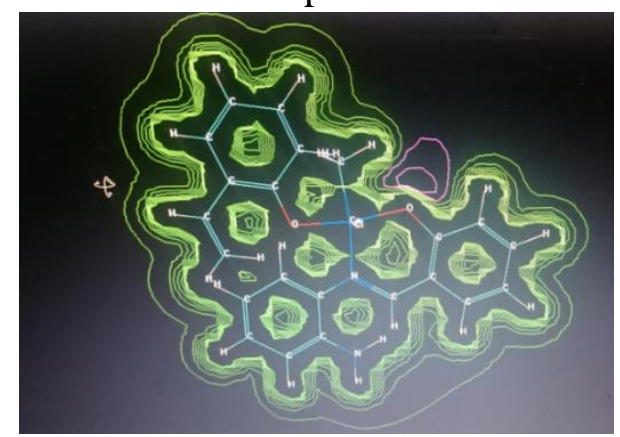

Electrostatic potential of Co

Scheme (4) Electrostatic Potential for prepared complexes.

\section{Acknowledgements}

The authors wish to thank Al-Nahrain University and University Kebangsaan Malaysia for all facilities offered and funding of this project.

\section{References}

[1] Osman A. H., Synthesis and Characterization of Cobalt (II) and Nickel(II) Complexes of Some Schiff Bases Derived from 3-hydrazino-6-methyl[1,2,4] triazin-5(4H)one, Transition Metal Chemistry, 31, 35-41, 2006

[2] Mohammed R. El-Haiti G. Ahmed A. Yousif E., Spectroscopic, physical and topography of photochemical process of PVC films in the presence of Schiff base metal complexes Polymers, Arabian Journal for Science and Engineering, 8, 1-13, 2016.

[3] Yousif, E., Salimon, J. and Salish, J., "New photo stabilizers for PVC based on some diorganotin (IV) complexes", J. Saudi Chem. Soc., 19, 133-141, 2015.

[4] Haddad R., and Rahimim Y., "Ultra Violet Spectra Studies of Polystyrene Films in Presence of Some Transition Metal Complexes with4-amino-5-pyridyl)-4h1,2,4-triazole-3-thiol", Oriental. J. Chem, 31 (1):591-596, 2015.
[5] Gupta K.C. Sutar A.K. "Catalytic Activities of Schiff Base Transition Metal Complexes," Coordination chemistry Reviews, 252: 1420-1450, 2008.

[6] Cozzi P. G., Metal-Salen Schiff base complexes in catalysis: practical aspects, Chemical Sociaty Reviews, 33: 410-422, 2004.

[7] B. Tu"rkkan B. Sariboga B. "Biological Activities of Schiff Bases and Their Complexes: A Review of Recent Works, Transition Metal Chemistry", 36: 679-684, 2011.

[8] Siji V. L., Sudarsanakumar M. R., Suma S., Synthesis, properties and crystal structures of nitrobenzoatocopper (II) complexes with pyrazinecarboxamide, Transition Metal Chemistry ,36:417- 424, 2011.

[9] Krishnamohan C. V., "Metal-Salen Schiff Base Complexes in Catalysis: Practical Aspects," Chemical. Crystal growth \& Design, 2: 465-474, 2002.

[10] Ahamad I. Prasad R. Quraishi M. A., Thermodynamic, electrochemical and quantum chemical investigation of some Schiff bases as corrosion inhibitors for mild steel in Hydrochloric acid solutions, Corrosion Science, 52, 933-942, 2010. 
[11] Antonijevic H. Petrovic M. "Copper Corrosion Inhibitors. A review, International Journal of Electrochemical Science", 3, 1-28, 2008.

[12] Sharghi H. Nasseri M.A. "Schiff-Base Metal (II) Complexes as New Catalysts in the Efficient, Mild and Regioselective Conversion of 1,2-Epoxyethanes to 2Hydroxyethyl Thiocyanates with Ammonium Thiocyanate", chemical society of japan, 76: 137-142, 2003.

[13] Gao W.T. Zheng Z., "Synthetic Studies on Optically Active Schiff-base Ligands Derived from Condensation of 2Hydroxyacetophenone and Chiral Diamines", Molecules, 7, 511-516, 2002.

[14] Vigato P.A. Tamburini S., "the Challenge of Cyclic and Acyclic Schiff Bases and Related Derivatives", Coordination Chemistry Reviews, 248, 1717-2128, 2004.

[15] Geary W. G., The Use of Conductivity Measurements in Organic Solvents for the Characterisation of Coordination Compounds, Coordination Chemistry Reviews, 7, 81-122, 1971.

[16] Nakamoto K. 3rd Edn. Wiley Interscience, New York, 1977.

[17] Shakir M., Islam K.S., Mohamed A.K., Shagufta M., Hasan S.S., Macrocyclic complexes of transition metals with divalent polyaza units, Transition Metal Chemistry, 24, 577-580, 1999.

[19] Singh D. P., Ramesh K, Singh J., Antibacterial activity and spectral studies of trivalent chromium, manganese, iron macrocyclic complexes derived from oxalyldihydrazide and glyoxal, Journal of Enzyme Inhibition and Medicinal Chemistry, 3, 883-889, 2009.

[20] Salih N., Salimon J., Yousif E., Synthesis and antimicrobial activities of $9 \mathrm{H}$-carbazole derivatives, Arabian Journal of Chemistry, 9, 781-786, 2016.

[21] Yousif E., Adil H., Farina Y., Synthesis and Characterization of Some Metal Ions with 2-amino Acetate Benzothiazole, Journal of Applied Sciences Research, 6(7), 879-882, 2010.

[22] Silverstein R.M. Bassler G.C. Morril T.C. Spectrometric Identification of Organic Compounds, 4th Ed., John Wiely and Sons Inc., New York 1981.
[23] Aswar A.S. Bansod A.D. Mahale R.G. "Synthesis, Structural Characterization, Electrical and Antimicrobial Studies of Some Divalent Metal Chelates", Journal of Indian Council of Chemists, 23: 10-12, 2006.

[24] Lever A.B.P. Inorganic Electronic Spectroscopy, 2nd ed., Elsevier, Amsterdam 1984.

[25] Yousif E., Abdalla M., Ahmed A., Salimon J., Salih N., Photochemical stability and photostabilizing efficiency of poly(methyl methacrylate) based on 2thioacetic acid-5-phenyl-1,3,4-oxadiazole Complexes, Arabian Journal of Chemistry, 9, 595-601, 2016.

[26] Mishra A. P., Khare M., Gautam S. K., Synthesis and Reactivity in Inorganic, Metal-Organic, and Nano-Metal Chemistry, 32, 1485-1500, 2002.

[27] Figgis B.N. Introduction to Ligand Field, Wiely eastern Ltd., New Delhi, 1976.

[28] B.K.Ra and Rachana Kumari, "Synthesis, Characterization and Antifungal Screening of $\mathrm{Ni}(\mathrm{II}), \mathrm{Cu}$ (II) and $\mathrm{Co}$ (II) Complexes with Nitrogen and Oxygen Containing Schiff Base", Asin Journal of chemistry,23:46254628, 2011.

[30] Dina A. Najeeb., "Synthesis, Characterization and Theoretical Studies of Transition Metal Complexes of 1,2 Phenyl (4Carboxy) Benzylidene", Int. J. Pharm. Sci. Rev. Res.,38(1), June, 223-226, 2016.

[31] Figgis B. Hitchman M. Ligand Field Theory and Its Applications. Wiley, New York 2000. 